\title{
The Heterogeneous Economic Impacts of Distance to High-Speed Railway Stations in China
}

\author{
Baocheng Wang ${ }^{1}$, Feng $\mathrm{Yu}^{2}$ \& Mengting Zhang ${ }^{3}$ \\ ${ }^{1}$ School of International Trade and Economics, Central University of Finance and Economics, China \\ ${ }^{2}$ School of Economics and Management, University of Science and Technology Beijing, China \\ ${ }^{3}$ School of Business, Ningbo University, China \\ Correspondence: Mengting Zhang, School of Business, Ningbo University, China. E-mail: \\ zhangmengting@nbu.edu.cn
}

Received: October 19, 2020

Accepted: November 26, 2021

Online Published: January 25, 2021

doi:10.5539/ijbm.v16n2p75

URL: https://doi.org/10.5539/ijbm.v16n2p75

\begin{abstract}
With the rapid development of High-speed Railway worldwide, particularly in China, its economic effect is increasingly prominent. In this paper, we claimed that the distance to HSR station rather than HSR connection affects its economic influence by examining the panel data of 333 prefectures during 1999-2013 in China. It is shown that cities would receive positive and significant economic gains if the distance between cities administrative center and the nearest HSR station is less than $10 \mathrm{~km}$. To address the potential endogenous problem, a least cost spanning tree network IV strategy based on Faber (2014) is adopted and further confirmed the robustness. Our finding provides scientific evidence of HSR station's location planning and is promising to optimize HSR's structural layout.
\end{abstract}

Keywords: High-speed railway, distance to high-speed railway station, per capita GDP

\section{Introduction}

"Wanna be rich? Build roads first!" Infrastructure construction is regarded as an engine of economic growth. High-speed railway (HSR) is one of the most significant technological breakthroughs in transport field. Since the first HSR route (Tokaido Shinkansen) opened in Japan in 1964, it has experienced a rapid development both in developed and developing countries. HSR has raised great enthusiasm worldwide for its prominent advantages and increasingly wide coverage. However, the empirical economic evaluation of HSR turns to be mixed.

Previously, economic evaluations on HSR in Japan (Bernard et al., 2019) and Europe (Vickerman, 1997), where HSR station is more likely to be built in the city center, were significantly positive. While in China, HSR connection was reported to lead to a reduction of GDP for peripheral regions due to the agglomeration effect (Qin, 2017; Yu et al., 2018). In China, HSR stations are usually located in rural areas or in outer suburbs according to the official news (Note 1) and online reports sources (Note 2) Is the location of HSR station the cause of the mixed results? With the prevalence of HSR construction worldwide, the answer to this question would be of great significance for policy makers. Thus, in this paper we aim to use China's HSR, the largest scale in the world, to fill this gap by studying the consequences of HSR station's location and quantifying the corresponding distance.

This paper belongs to the cast literature on the economic effects of transportation infrastructure and hoping to establish a causal link between economic activity and railway networks. Since transportation has long been known as an essential component of growth, there have been rich research on the economic consequences of transportation infrastructure, such as railway (Hornung, 2015; Donaldson, 2018; Donaldson \& Hornbeck, 2016; Swisher, 2017), highway (Juan \& Gonzalo, 2014; Faber, 2014; Bosker, Deichmann \& Robert, 2015), and high-speed railways (hereinafter referred as HSR) (Lin, 2016; Qin, 2017; Xu, 2019). However, none of these papers analyzes the influence of spatial relative of HSR station and the cities. We aim to fill this gap in the literature.

As a result of the rapid development of HSR, research on the impacts of HSR networks has become a hot topic (Zheng \& Kahn, 2013; Wu et al., 2013; Shaw et al., 2014). Within the literature on HSR, our paper mostly closely related to the recent but expanding strand of literature that analyze the heterogeneous influences of HSR. 
Ke et al. (2017) find that the gain for local economies is greater for cities that are more industrialized, with more ability of the service sector to absorb enough labor, and with better supporting infrastructure. Ahlfeldt \& Feddersen (2015) and Yu et al.(2019) find that high - speed railway connection has led to a reduction in GDP per capita for connected peripheral prefectures. However, seldom attention has been paid to the impact of HSR station. Our work complements these earlier studies by considering HSR station's moderation influence. To summarize, our paper is in line with the literature that finds heterogeneous economic effects of HSR, bur differ from the literature by examining a previously overlooked aspect.

The rest of the paper is organized as follows: sections 2 presents the data and methodologies; Section 3 describes empirical results; Section 4 concludes.

\section{Data and Methodologies}

\subsection{Background}

The rapid construction of HSR in China provides us with an ideal empirical setting to detect the impact of HSR on economic growth. Specifically, with the open of the first Intercity Line between Beijing and Tianjin in 2008, China's HSR era began. By the end of 2016, HSR has covered 177 prefectural-level cities, almost inevitably connecting both large metropolitan centers of production as well as small-to-median peripheral counties, with total HSR length of $22,000 \mathrm{~km}$.

Spatially, the HSR network in China Mainland had formed a complete network in the eastern and central regions and began to expand westward. According to the China Mid-long Railway Planning, the extent of the HSR network could reach $41,000 \mathrm{~km}$ forming a eight vertical and eight horizontal spatial framework. consists of eight north-south and eight east-west rail corridors. The north-south corridors include Beijing-Shanghai, BeijingGuangzhou-Shenzhen-Hong Kong, Beijing-Harbin, Huhhot-Nanning, Beijing-Kunming, Baotou-Haikou, and Lanzhou-Guangzhou. The east-west corridors are Suifenhe-Manchuria connecting Heilongjiang and east part of Inner Mongolia, Beijing-Lanzhou, Qingdao-Yinchuan, Lianyungang-Urumqi (Land Bridge), an HSR along the Yangtze River (from Shanghai to Chengdu), Shanghai-Kunming, Xiamen-Chongqing, and GuangzhouKunming. It is expected that HSR can substantially complement the modern comprehensive transportation network of China.

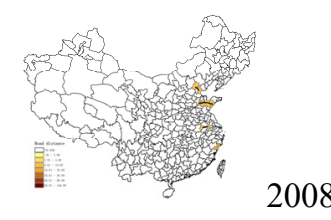

2008

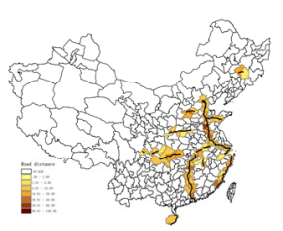

2011

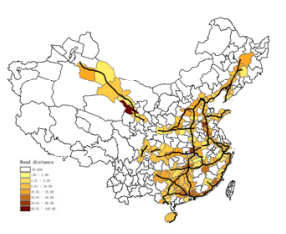

2014

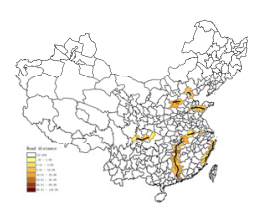

2009

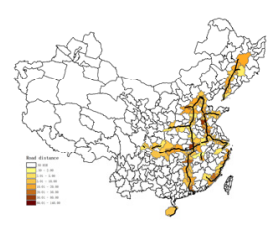

2012

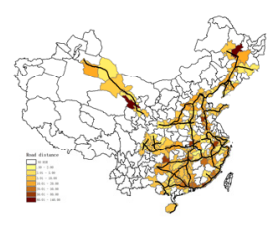

2015

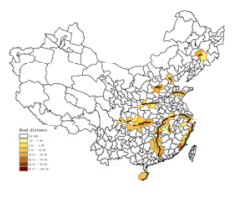

2010

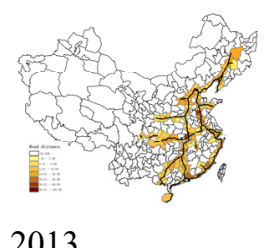

2013

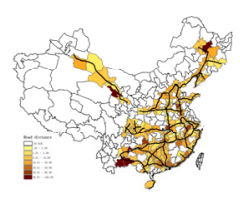

2016

Figure 1. Construction of China's HSR network from 2008 to 2016

Notes: The lines in bold black are high-speed railway lines in operation by the end of that year. The cities are marked in color according to the distance of the city centers from their nearest HSR stations. 
However, HSR stations are either located in surrounding rural areas close to the central urban area or in outer suburbs in China, with the average distance of the city center to its nearest HSR station of $34 \mathrm{~km}$. Figure 1 illustrates the development of China's HSR and the evolution of distance between city center and HSR stations during 2008 and 2016. Two stylized facts were suggested. First, the distances of the city center to its nearest HSR stations become larger with the development. Second, the distance varied across regions (Note 3). Some HSR stations are close to urban areas, while others are a few hundred kilometers away. Since existed studies has revealed that HSR counties close to core city benefit more compared with the ones far away (Qin, 2017; Li \& Xu, 2018; Yu et al., 2019), it is interesting to examine the possible heterogeneous economic impacts of distance to HSR stations.

\subsection{Data}

The prefectural-level socioeconomic data are taken from China City Statistical Yearbooks from 1999 to 2013 , including population, GDP, fixed-asset investment, local government revenue and expenditure, resident income, total revenue of industrial firms, and e.t.c. Some missing data are complemented by China Regional Economic Statistical Yearbooks. These data provide a prefectural-level economic information system dividing the surface of China into 333 prefectures. The prefectural-level socioeconomic data are used as explained variable and control variable in this paper.

Our explanatory variable is the distance between city center and its nearest HSR station. City center refers to the location of the local government in our work, and their geographic location is labelled longitude and latitude with the help of Coordinate Pickup System of Baidu (Note 4). HSR is defined as "railway lines running at an average speed of $250 \mathrm{~km} / \mathrm{h}$ or more, or passenger-dedicated-intercity-lines running at an average speed of $200 \mathrm{~km} / \mathrm{h}$ or more" (Note 5) in China. Information about HSR regarding construction date and open date is drawn from China Railway Statistical Yearbook or official news and announcements. Since our analysis is on the prefectural level, it is natural that there are usually more than one HSR station for a city, which make it meaningful to sort out whether and to what degree does the relative distance between HSR station and the city mater matters, The detailed basic information about the HSR station such as name, number and opening date, is obtained from the official railway service website (www.12306.cn), and station's location is also labelled with longitude and latitude By importing HSR connection and HSR station information into GIS, we calculate and identify the nearest HSR station for each cities.

\subsection{Identification Strategy}

To analyze the possible heterogeneous impacts of distance to HSR stations, we compute the distance (unit: km) from the centroid of each city to the centroid of its nearest HSR stations and introduce the distance and squared distance into the model that extended from Xu (2017). The baseline estimation uses a difference-in-differences specification.

$$
\ln (G D P \text { per })_{c t}=\lambda_{1} H_{S R} R_{c t}+\lambda_{2} \text { Road distance }_{c t}+\lambda_{3} Z_{c t}+\text { Year }_{t}+\text { City }_{c}+u_{c t}
$$

where $\ln (G D P \text { per })_{c t}$ indicates the per capital GDP of prefecture $c$ in year $t(1999-2013)$ in $\operatorname{logs}$. $H S R_{c t}$ is a dummy variable that denotes whether prefecture $c$ was connected to the HSR network. Road distance Rt $_{\text {s }}$ indicates the road distance from the centroid of prefecture $c$ to its nearest HSR stations in year $t$. We use Arc-GIS to find the closest HSR station, then import the site into Baidu map (https://map.baidu.com/) to retrieve the navigation path distance from HSR station to the city center (Note 6). $Z_{c t}$ is a vector of prefecture control variables, including airport dummy, highway intensity, traditional railway dummy, and e.t.c. Year $_{t}$ is the year fixed effect, while City $_{c}$ is the city fixed effect. Besides, to control the potential heteroscedasticity and space related problems, we performed cluster adjustment of the standard deviation at the city level as Bertrand and Duflo (2004).

As stated by the Ministry of Railway of China, the HSR aims to connect all provincial capitals and other major cities that are expected to have a higher economic growth potential. Thus, the OLS estimates would impose a bias in the case of the correlation between per capita GDP and HSR connection. To reduce the endogeneity issue of this type, $\mathrm{Yu}$ et al. (2018) excluded the 32 provincial capitals and sub-provincial cities, resulting in 301 prefecture-level city samples from 1999 to 2013. To further address this endogenous placement problem, they follow Faber (2014) and construct a least-cost path spanning tree network as an instrument variable (IV) of the HSR network. Inspired by them, we also adopt the least-cost path spanning tree network as an IV to handle the endogeneity issue of HSR connection. The vector geo-spatial data are drawn from China Geospatial Cloud (http://www.gscloud.cn/), Chinese Administrative Division Vector Diagram (http://bzdt.nasg.gov.cn/index.jsp) and China Transportation Atlas from 1999 to 2013. The Digital Elevation Model (DEM) data used for IV 
construction are obtained from China Geospatial Cloud.

\section{Empirical Results}

Controlling for other kinds of transportation, year fixed effect and city fixed effect, baseline regression's results in column (1) of Table 1 present that HSR connection negatively affects prefecture-level per capita GDP, the ATE (average treatment effect) is about $6.36 \%$. Results of Column (2) show the negative effects of HSR connection on prefectures disappear (with no statistical significance) while the road distance negatively affected the explained variable, which suggests that HSR station's location rather than HSR connection contributes to its effect on the cities' per capita GDP. However, the squared road distance in Column (3) shows no significant effects suggesting distance doesn't have quadratic effect.

To address the endogenous problem, an IV (instrument variable) strategy is adopted and the result is shown in column (4) and column (5). The F-statistics of the first stage is more than 10, indicating that the IV is an effective one, saying relevant to the actual HSR placement and irrelevant to economic development. The result is in line with the main findings and further verified the conclusion. To quantify the corresponding distance, we further divide the sample into subgroups according to the distance between the city center and its nearest HSR station (as $0-10 \mathrm{~km}, 10-30 \mathrm{~km}, 30-50 \mathrm{~km}$, and $>50 \mathrm{~km}$ ). From columns (6)-(9), we find that the initial positive economic effect of distance declined and disappeared beyond $10 \mathrm{~km}$.

To our understanding, social factor and economic factor are two of the main reasons to scientifically explain the impact of HSR station's location. On the one hand, HSR mainly competes with air travel for longer trips and with conventional railway/highway over shorter lines (Zheng and Kahn, 2013). For example, the busiest line is median-to-short one that connects two central cities, such as Beijing-Tianjin, Shanghai-Nanjing, and Guangzhou-Shenzhen lines (Lin, 2017). In this context, when the HSR station is built "far away" from the city center, poor access to HSR might offset its time-saving advantages. On the other hand, the financial costs of traveling by HSR increase significantly (Lin, 2017; Yu et al., 2018). For high-income passengers whose opportunity costs of time are high would prefer HSR, but not for low-income one. Considering that the high-income population tends to work in the city center, the "remote" HSR station decreases their potential benefits from HSR access. Thus, influence of HSR station site selection on travel efficiency may curb scholarly understanding of the contradictory economic outcomes of HSR in China from developed countries.

Table 1. The impact of HSR on per capita GDP

\begin{tabular}{|c|c|c|c|c|c|c|c|c|c|}
\hline & (1) & (2) & (3) & (4) & (5) & (6) & (7) & (8) & (9) \\
\hline \multirow[t]{2}{*}{ VARIABLES } & OLS & OLS & OLS & IV & IV & OLS & OLS & OLS & OLS \\
\hline & $\begin{array}{l}\text { per capital } \\
\text { GDP }\end{array}$ & $\begin{array}{l}\text { per } \\
\text { capital } \\
\text { GDP } \\
\end{array}$ & $\begin{array}{l}\text { per } \\
\text { capital } \\
\text { GDP } \\
\end{array}$ & $\begin{array}{l}\text { per } \\
\text { capital } \\
\text { GDP }\end{array}$ & $\begin{array}{l}\text { per } \\
\text { capital } \\
\text { GDP }\end{array}$ & $\begin{array}{l}\text { per } \\
\text { capital } \\
\text { GDP } \\
\end{array}$ & $\begin{array}{l}\text { per } \\
\text { capital } \\
\text { GDP }\end{array}$ & $\begin{array}{l}\text { per capital } \\
\text { GDP }\end{array}$ & $\begin{array}{l}\text { per capital } \\
\text { GDP }\end{array}$ \\
\hline \multirow[t]{2}{*}{ HSR } & $-0.0636^{* * *}$ & 0.00671 & 0.00260 & & & $-0.107^{* * *}$ & $-0.133^{* * *}$ & $-0.0626^{* * *}$ & $-0.0621^{* * *}$ \\
\hline & $(-3.43)$ & $(0.19)$ & $(0.06)$ & & & $(-3.73)$ & $(-3.30)$ & $(-3.29)$ & $(-3.31)$ \\
\hline \multirow[t]{2}{*}{ Road distance } & & $-0.0338^{* *}$ & -0.0291 & & -1.906 & & & & \\
\hline & & $(-2.36)$ & $(-0.77)$ & & $(-1.44)$ & & & & \\
\hline \multirow[t]{2}{*}{ Road distance $^{2}$} & & & -0.00117 & & & & & & \\
\hline & & & $(-0.14)$ & & & & & & \\
\hline \multirow[t]{2}{*}{ IV } & & & & $-0.279^{* * *}$ & 5.159 & & & & \\
\hline & & & & $(-2.60)$ & $(1.52)$ & & & & \\
\hline \multirow{2}{*}{$\begin{array}{l}\text { Station } 0-10 \mathrm{~km} \\
\text { road distance }\end{array}$} & & & & & & $0.0648^{* *}$ & & & \\
\hline & & & & & & $(2.07)$ & & & \\
\hline \multirow{2}{*}{$\begin{array}{l}\text { Station } 10-30 \mathrm{~km} \\
\text { road distance }\end{array}$} & & & & & & & -0.0506 & & \\
\hline & & & & & & & $(-1.42)$ & & \\
\hline \multirow{2}{*}{$\begin{array}{l}\text { Station } 30-50 \mathrm{~km} \\
\text { road distance }\end{array}$} & & & & & & & & -0.0518 & \\
\hline & & & & & & & & $(-0.87)$ & \\
\hline \multirow{3}{*}{$\begin{array}{l}\text { Station }>50 \mathrm{~km} \\
\text { road distance }\end{array}$} & & & & & & & & & $-00976^{* * *}$ \\
\hline & & & & & & & & & \\
\hline & & & & & & & & & $(-4.19)$ \\
\hline
\end{tabular}




\begin{tabular}{lcccccccccc}
\hline $\begin{array}{l}\text { Other mode of } \\
\text { transportation }\end{array}$ & YES & YES & YES & YES & YES & YES & YES & YES & YES \\
Year fixed effect & YES & YES & YES & NO & NO & YES & YES & YES & YES \\
City fixed effect & YES & YES & YES & NO & NO & YES & YES & YES & YES \\
Observations & 4451 & 4451 & 4451 & 299 & 299 & 4451 & 4451 & 4451 & 4451 & 0.947 \\
R-squared & 0.947 & 0.947 & 0.947 & 0.740 & 0.740 & 0.947 & 0.947 & 0.947 & \\
F-statistics & & & & 20.346 & 20.346 & & & & & \\
\hline
\end{tabular}

Notes. Other mode of transportation includes airport dummy, highway intensity and railway dummy at prefectural level. Robust standard errors are clustered at the city level and reported in parentheses; $* * * \mathrm{p}<0.01, * * \mathrm{p}<0.05, * \mathrm{p}<0.1$.

Moreover, we conduct several sensitivity analyses for robust check (Table 2). First, dividing into subgroups by different period (column 1-4). Our whole sample window is from 1999 to 2013, and the subsamples including subgroup of 2001-2003, 2003-2013, 1999-2012 and 1999-2011 respectively. Factors such as WTO entry, enterprises dataset's quality and debt crisis are taken in to consideration. Second, using the line distance (Note 7) as an alternative measure (column 5). Third, further include other city character control variables, such as economic structure and population (column 6 and 7). Fourth, use the year-province effect to control for year with province time trends (column 8 ). All these results are consistent with the ones from basic regression, which means supporting the main findings.

Table 2. Robust checks

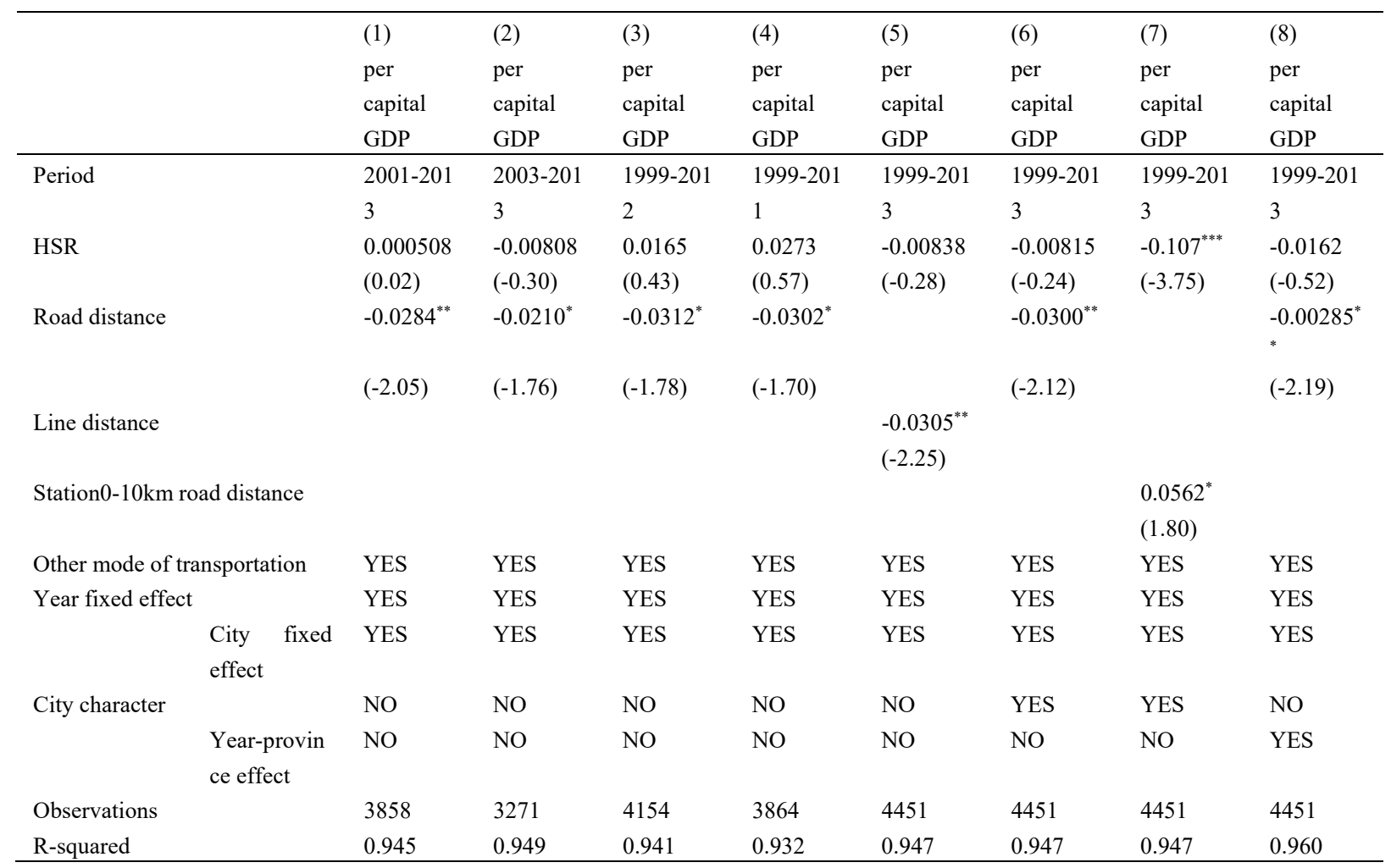

Notes. Other mode of transportation includes airport dummy, highway intensity and railway dummy at prefectural level. City character includes economic structure and population. Robust standard errors are clustered at the city level and reported in parentheses; ${ }^{* * *} \mathrm{p}<0.01, * *$ $\mathrm{p}<0.05, * \mathrm{p}<0.1$.

\section{Conclusion}

This paper provides empirical evidence of the heterogeneous economic impacts of HSR of distance to HSR stations. By cooperating China's city data, HSR data and geographic data, we find that prefectures benefit from HSR connection only if the city center is within $10 \mathrm{~km}$ road distance from the nearest HSR station. The conclusion that distance between city center and the nearest HSR station negatively affects HSR's economic effect is robust in a series of checks, such as adjusting sample window, using alternative explanatory variable, 
further including control variables and controlling more combined fixed effect.

Based on the results, it is safely to say that centrally located HSR station can reinforce the concentration of economic activity in metropolitan regions, rather than diffusing to the periphery. Our findings can be useful for policy makers of cities that having HSR in preparation or under construction. More precisely, HSR station's location can be an important way to moderate and reinforce HSR's economic benefits for the city given the fact that it is not easy to adjust route planning. Therefore, apart from construction cost, the HSR station accessibility is another vital factor in HSR planning that should be put into consideration as it can to a large extent determine whether the region can receive positive economic effects by HSR projects or not.

\section{Funding}

This research is supported by National Nature Science Foundation of China [71673182].

\section{References}

Banejee, A., Duflo, E., \& Qian, N. (2020). On the road: Access to transportation infrastructure and economic growth in China. Journal of Development Economics, 145. https://doi.org/10.1016/j.jdeveco.2020.102442

Baum-Snow, N. (2007). Did highways cause suburbanization? Quarterly Journal of Economics, 122(2), 775-805. https://doi.org/10.1162/qjec.122.2.775

Bernard, A., Moxnes, A., \& Saito, Y. (2019). Production Networks, Geography and Firm Performance. Journal of Political Economy, 127(2), 639-688. https://doi.org/10.1086/700764

Bertrand, M., Duflo, E., \& Mullainathan, S. (2004). How Much Should We Trust Differences-In-Differences Estimates? Quarterly Journal of Economics, 119, 249-275. https://doi.org/10.1162/003355304772839588

Donaldson, D. (2018). Railroads of the raj: estimating the impact of transportation infrastructure. American Economic Review, 108(4-5), 899-934. https://doi.org/10.1257/aer.20101199

Donaldson, D., \& Hornbeck, R. (2016). Railroads and American economic growth: A "market access" approach. The Quarterly Journal of Economics, 131(2), 799-858. https://doi.org/10.1093/qje/qjw002

Faber, B. (2014). Trade integration, market size, and industrialization: evidence from China's National Trunk Highway System. The Review of Economic Studies, 81(3), 1046-1070. https://doi.org/10.1093/restud/rdu010

Lin, Y. (2017). Travel Costs and Urban Specialization Patterns: Evidence from China's High Speed Railway System. Journal of Urban Economics, 98, 98-123. https://doi.org/10.1016/j.jue.2016.11.002

Qin, Y. (2017). No county left behind? The distributional impact of high-speed rail upgrades in China. Journal of Economic Geography, 17, 489-520. https://doi.org/10.1093/jeg/lbw013

Vickerman, R. (1997). High-speed rail in Europe: experience and issues for future development. The Annals of Regional Science, 31(1), 21-38. https://doi.org/10.1007/s001680050037

$\mathrm{Xu}, \mathrm{M}$. (2017). Riding on the new silk road: quantifying the welfare gains from high-speed railways, Job Market paper. Retrieved from http://www.mingzhixu.com/

Yu, F., Lin, F., Tang, Y., \& Zhong, C. (2018). High-speed railway to success? The effects of HSR connection on regional economic development in China. Journal of Regional Science. https://doi.org/10.1111/jors.12420

\section{Notes}

Note 1. http://news.gaotie.cn/

Note 2. http://news.gaotie.cn/

Note 3. The top five cities regarding distance to the nearest HSR station are Jiujiang $(0.5 \mathrm{~km})$, Shenzhen $(1.9 \mathrm{~km})$, Dazhou $(2.1 \mathrm{~km})$, Handan $(2.3 \mathrm{~km})$, and Zhenjiang $(2.4 \mathrm{~km})$, while the bottom five cities are Fuzhou $(46.3 \mathrm{~km})$, Jieyang $(55.5 \mathrm{~km})$, Xiaogan $(61.3 \mathrm{~km})$, Liupanshui $(139.6 \mathrm{~km})$ and Ganzhou $(259.9 \mathrm{~km})$.

Note 4. URL: https://api.map.baidu.com/lbsapi/getpoint/index.html.

Note 5. Please see http://www.nra.gov.cn/ztzl/hyjc/kjcxx/kp/201605/t20160526_24387.html for the summary of the definitions of HSR by the government of China.

Note 6. The line distance is calculated by Arc-GIS using latitude and longitude data of HSR stations and city centers. 
Note 7. Different from the road distance used in basic regression, line distance refers to the straight-line distance. In general, road distance is bigger than the line distance.

\section{Appendix}

Table A.1. The distribution of distances of the HSR stations across the top five and bottom five cities

\begin{tabular}{|c|c|c|c|c|c|c|c|c|c|}
\hline & City & $\begin{array}{l}\text { City } \\
\text { longitud } \\
\text { e }\end{array}$ & $\begin{array}{l}\text { City } \\
\text { latitude }\end{array}$ & $\begin{array}{l}\text { The number of } \\
\text { HSR stations } \\
\text { located in the } \\
\text { city }\end{array}$ & $\begin{array}{l}\text { The nearest } \\
\text { station }\end{array}$ & $\begin{array}{l}\text { The } \\
\text { nearest } \\
\text { station } \\
\text { longitude }\end{array}$ & $\begin{array}{l}\text { The } \\
\text { nearest } \\
\text { station } \\
\text { latitude }\end{array}$ & $\begin{array}{l}\text { The linear } \\
\text { distance } \\
(\mathrm{km})\end{array}$ & $\begin{array}{l}\text { The road } \\
\text { distance } \\
(\mathrm{km})\end{array}$ \\
\hline \multirow{5}{*}{$\begin{array}{l}\text { The top } \\
\text { five } \\
\text { cities }\end{array}$} & Jiujiang & 116.00 & 29.70 & 2 & $\begin{array}{l}\text { Jiujiang } \\
\text { station }\end{array}$ & 116.01 & 29.71 & 0.3 & 0.5 \\
\hline & Shenzhen & 114.11 & 22.55 & 4 & $\begin{array}{l}\text { Futian } \\
\text { station }\end{array}$ & 114.06 & 22.54 & 0.4 & 1.9 \\
\hline & Dazhou & 107.50 & 31.22 & 1 & $\begin{array}{l}\text { Dazhou } \\
\text { station }\end{array}$ & 107.46 & 31.2 & 1.7 & 2.1 \\
\hline & Handan & 118.48 & 36.62 & 3 & $\begin{array}{l}\text { Handan east } \\
\text { station }\end{array}$ & 114.57 & 36.63 & 2.1 & 2.3 \\
\hline & Zhenjiang & 119.45 & 32.20 & 7 & $\begin{array}{l}\text { Zhenjiang } \\
\text { station }\end{array}$ & 119.44 & 32.2 & 1.2 & 2.4 \\
\hline \multirow{5}{*}{$\begin{array}{l}\text { The } \\
\text { bottom } \\
\text { five } \\
\text { cities }\end{array}$} & Fuzhou & 116.35 & 28.00 & 1 & $\begin{array}{l}\text { Fuzhou east } \\
\text { station }\end{array}$ & 116.62 & 28.27 & 42.6 & 46.3 \\
\hline & Jieyang & 116.34 & 23.54 & 1 & $\begin{array}{l}\text { Puning } \\
\text { station }\end{array}$ & 116.2 & 23.27 & 36 & 55.5 \\
\hline & Xiaogan & 113.92 & 30.93 & 2 & $\begin{array}{l}\text { Hanchuan } \\
\text { station }\end{array}$ & 113.82 & 30.55 & 43.9 & 61.3 \\
\hline & Liupanshui & 104.83 & 26.60 & 1 & $\begin{array}{l}\text { Panzhou } \\
\text { station }\end{array}$ & 104.58 & 25.8 & 104.2 & 139.6 \\
\hline & Ganzhou & 114.93 & 25.83 & 2 & $\begin{array}{l}\text { Lechang } \\
\text { east station }\end{array}$ & 113.4 & 25.12 & 174.4 & 259.9 \\
\hline
\end{tabular}

\section{Copyrights}

Copyright for this article is retained by the author(s), with first publication rights granted to the journal.

This is an open-access article distributed under the terms and conditions of the Creative Commons Attribution license (http://creativecommons.org/licenses/by/4.0/). 